\title{
Genetic profiling of auto-inflammatory disorders in patients with periodic fever: a prospective study
}

\author{
Carlo De Pieri ${ }^{1 *}$, Josef Vuch², Anna Monica Bianco ${ }^{1}$, Francesca Barbieri ${ }^{2}$, Serena Pastore ${ }^{3}$, Luca Ronfani ${ }^{1}$, \\ Sergio Crovella ${ }^{3}$, Andrea Taddio ${ }^{3}$, Giovanni Maria Severini ${ }^{1}$, Aberto Tommasini ${ }^{1}$
}

From 21st European Pediatric Rheumatology (PReS) Congress

Belgrade, Serbia. 17-21 September 2014

\section{Introduction}

Hereditary periodic fevers (HPF) are an emerging group of auto-inflammatory disorders. Although this group includes five well definite disorders, overlap of phenotypes can be often observed making the diagnosis more difficult. Although genetic diagnostics is currently available for different periodic fevers, many patients will require subsequent analyses for different genes. The selection of patients for genetic analysis is also not easy, despite scoring systems to assist the choice have been developed (Gaslini score).

\section{Objectives}

We tested if a novel approach based on the simultaneous sequencing of HPF-related genes, can improve the diagnostics in this field.

\section{Methods}

Patients consecutively referred to the unit of pediatric rheumatology of the IRCCS Burlo Garofolo from March 2012 to April 2013 for unexplained periodic fever since 1 year or more, still active at the time of recruitment. In particular we considered the following three groups: 1) patients already studied for a single candidate gene with negative results; 2) atypical pharyngitis, adenitis and aphthae (PFAPA) syndrome based on absent response to steroids or relapse after tonsillectomy; 3 ) other patients with periodic fever with multi-systemic involvement.

Structured chart was used to collect personal data and information about episode duration and clinical features,

${ }^{1}$ institute For Maternal And Child Health Irccs Burlo Garofolo, Trieste, Italy Full list of author information is available at the end of the article including symptoms, laboratory and imaging investigations results, response to treatments (steroids, colchicine).

In all subjects the simultaneous sequencing of MEFV, MVK, TNFRSF1A, NLRP3, NLRP12 was performed after fragment amplification in a single plate with specific primers with touch-down PCR.

\section{Results}

A total of 43 patients were included in the study: 8 were previously evaluated for single genes (7 MVK, 2 NLRP3, 1 MEFV); 11 had atypical PFAPA (no response to glucocorticoids of tonsillectomy) ; 23 had periodic fever with multisystemic symptoms suspicious of no specific HPF.

According to the international consensus for the interpretations of genetic results, we could find: definitely causative mutations (V377I/V377I mutation in MVK; H304Y in NLRP12); low penetrance mutation (2 R92Q in TNFRSF1A); heterozygous high penetrance mutations (2 E148Q mutation in MEFV, 1 complex allele P369SR408Q in MEFV, 1 V377I in MVK); single or multiple variants of unclear significance (overall 17, of which, 8 F402L variant in NLRP12, 5 Q703K variant in NLRP3). No variant in the five gene was found in 18 subjects.

Statistical analysis showed that the failure of glucocorticoids was significantly more frequent in subjects with any positive results to genetic analysis compared with subjects with negative genetic results.

\section{Conclusion}

Simultaneous sequencing of multiple HPF-related genes can help diagnosing in few cases. In most cases a wide range of genetic abnormalities is observed, ranging from low penetrance mutations to complex genotypes with multiple variants in different genes. 


\section{Disclosure of interest}

None declared.

\section{Authors' details}

${ }^{1}$ institute For Maternal And Child Health Irccs Burlo Garofolo, Trieste, Italy.

${ }^{2}$ department Of Medicine And Surgery And Health, University Of Trieste,

Trieste, Italy. ${ }^{3}$ institute For Maternal And Child Health Irccs Burlo Garofolo,

Trieste, Italy ,Department Of Medicine And Surgery And Health, University Of

Triestedepartment Of Medicine And Surgery And Health, University Of

Trieste, Trieste, Trieste, Italy.

Published: 17 September 2014

doi:10.1186/1546-0096-12-S1-P83

Cite this article as: De Pieri et al:: Genetic profiling of auto-inflammatory disorders in patients with periodic fever: a prospective study. Pediatric

Rheumatology 2014 12(Suppl 1):P83.

Submit your next manuscript to BioMed Central and take full advantage of:

- Convenient online submission

- Thorough peer review

- No space constraints or color figure charges

- Immediate publication on acceptance

- Inclusion in PubMed, CAS, Scopus and Google Scholar

- Research which is freely available for redistribution

Submit your manuscript at www.biomedcentral.com/submit
Ciomed Central 